\title{
Abdominal Pregnancy: About a Case Observed at the Maternity of the Community University Hospital Center, Bangui, Central African Republic
}

\author{
G. D. Kossa-Ko-Ouakoua1 ${ }^{*}$, A. Koirokpi'1, S. Matoulou-Mbala Wa-Ngogbe1, R. M'Betid-Degana², \\ E. Serdouma ${ }^{2}$, F. Kouandongui Bangue Songrou ${ }^{3}$, G. R. Dotte ${ }^{4}$, N. R. Ngbale', A. Sepou ${ }^{1}$
}

\begin{abstract}
${ }^{1}$ Department of Gynecology and Obstetrics, Community University Hospital Center, Bangui, Central African Republic
${ }^{2}$ Department of Gynecology and Obstetrics, Sino-Central African Friendship University Hospital Center, Bangui, Central African Republic

${ }^{3}$ Medical Imaging Department, Community University Hospital Center, Bangui, Central African Republic ${ }^{4}$ Medical Oncology Department, Community University Hospital Center, Bangui, Central African Republic Email: *kossa2002fr@yahoo.fr
\end{abstract}

\begin{abstract}
How to cite this paper: Kossa-Ko-Ouakoua, G.D., Koirokpi, A., Wa-Ngogbe, S.M.M., M’Betid-Degana, R., Serdouma, E., Songrou, F.K.B., Dotte, G.R., Ngbale, N.R. and Sepou, A. (2021) Abdominal Pregnancy: About a Case Observed at the Maternity of the Community University Hospital Center, Bangui, Central African Republic. Open Journal of Obstetrics and Gynecology, 11, 296302.
\end{abstract}

https://doi.org/10.4236/ojog.2021.113029

Received: January 28, 2021

Accepted: March 15, 2021

Published: March 18, 2021

Copyright $\odot 2021$ by author(s) and Scientific Research Publishing Inc. This work is licensed under the Creative Commons Attribution International License (CC BY 4.0).

http://creativecommons.org/licenses/by/4.0/

\begin{abstract}
Abdominal pregnancy is a life threat to both mother and fetus requiring surgery regardless of the age of pregnancy. We report a case of abdominal pregnancy, delivered by laparotomy with a live newborn. This is a 31 -year-old woman with 34 weeks and 2 days of amenorrhea whose ultrasound showed an abdominal pregnancy. Laparotomy extracted a newborn female weighing 3000 grams with APGAR at birth rated at 7/10 at one minute. The postoperatives were simple. The patient was discharged on the 14th postoperative day on $20 \mathrm{mg}$ methrotrexate injection once a week for four weeks.
\end{abstract}

\section{Keywords}

Abdominal Pregnancy, Laparotomy, Live Newborn, Central African Republic

\section{Introduction}

Entity of ectopic pregnancies, abdominal pregnancy is defined as the implantation and development of the fertilized egg in part or in whole in the abdominal cavity in a primary or usually secondary manner [1] [2]. Of the two possible locations of ectopic pregnancies, the vast majority of cases (95\%) of which are tubal pregnancy and the rare extra tubal minority (5\%), abdominal pregnancy occupies the last place behind ovarian pregnancies $(3.2 \%)$ and cervical $(1.5 \%)$ with 
$1.3 \%$ [3]. Early abdominal pregnancy is distinguished from advanced abdominal pregnancy diagnosed after 20 weeks of amenorrhea [4]. Progressive forms beyond the 5th month are exceptional in developed countries, but frequent in those with low medical density [5] [6] [7] [8] [9]. Its primitive form is rare, as is its evolution over time with excessive perinatal mortality. In developing countries, the life of the mother is not so spared in some cases due to lack of resuscitation means and a lack of technical facilities. It is for this reason that Correa sees it as one of the reflections of underdevelopment [7] [8]. In this article, we report a case of abdominal pregnancy, delivered by laparotomy with a live newborn, observed in the maternity of the Community University Hospital Center of Bangui in Central African Republic in September 2018.

\section{Observation}

This is a 31-year-old patient, 4th gravida, 2nd para with the notion of 2 abortions. She had no specific medical history and was not using contraception. Her last period date would go back to December 22, 2017 for a period of five (05) days.

In May 2018, she consulted for a notion of amenorrhea associated with nausea occurring in waves, vomiting occurring in the morning on an empty stomach or after meals, sialorrhea and constipation but without genital bleeding.

On clinical examination, the patient was in good general condition with stained conjunctivae. Blood pressure and pulse were normal. She was afebrile. The abdomen was enlarged, deformed and measured $18 \mathrm{~cm}$. The fetal heart sounds were heard above the umbilicus. The pelvic exam noted that the uterus increased slightly, the vulva clean and the cervix closed on vaginal examination.

The X-ray of the abdomen without preparation and magnetic resonance imaging (MRI) were not performed. Conversely, abdominal ultrasound by $3.5 \mathrm{MHz}$ probe confirmed the diagnosis of an evolving abdominal pregnancy of $20 \mathrm{WA}+$ 5 days by measuring the various biometric parameters (cranial perimeter, biparietal, abdominal perimeter, femoral length.). The uterus was empty with a visible line of emptiness but slightly increased in size. The placenta was outside the uterine cavity bathed in peritoneal fluid.

Despite the risks to the mother and the fetus, the patient nevertheless opted for the continuation of the pregnancy. Rigorous surveillance was then instituted by prescribing close contacts. Unfortunately, the patient only honored three (03) contacts and received no vaccination or chemo prophylaxis for malaria except iron supplementation. Providencia liquefaciens vaginitis associated with Gardnerella vaginalis vaginosis were discovered during these three contacts as well as malaria with 680 parasites per $\mathrm{mm}^{3}$ treated with Cofantrine (Artemether $+\mathrm{Lu}$ mefantrine) and a urinary tract infection with Klebsiella onythrace sensitive to Chloramphenicol, with Gentamicin, Ofloxacin and Tetracycline but treated with Chloramphenicol.

At 34 WA + 2 days, a transverse suprapubic Pfannenstiel laparotomy allowed 
the extraction of a live F-sex newborn weighing 3000 grams with APGAR at 7/10 at 1 minute and showing no malformation.

After ligation and sectioning of the umbilical cord, a little hemorrhagic placenta adhering to the posterior surface of the uterine fundus as well as to the omentum was found. A partial ablation by pocket-to-pocket dissection was performed.

Due to a lack of red cell suspensions, whole blood bags were administered. Drains were put in and removed a few days later. Thromboprophylaxis under platelet control was instituted for 10 days as well as iron therapy for 30 days. The postoperative follow-up was straightforward and the patient was discharged from the hospital on D14. Methotrexate-based chemotherapy was started for 4 weeks at a dose of $1 \mathrm{mg} / \mathrm{kg}$.

A few days later, the newborn transferred to pediatrics died of prematurity and neonatal infection. Note that a complete antenatal corticosteroid therapy was done before the operation.

\section{Discussion}

Abdulcasis would be the first to describe a case of abdominal pregnancy in the tenth century [1].

\subsection{Epidemiology}

In our daily practice, abdominal pregnancy remains a rare disease of ectopic pregnancy [3]. Its frequency is not the same in the regions. High in countries with low medical density where her diagnosis is also later [9]-[15], the frequency of abdominal pregnancy is low in countries with high medical density such as pointed out Sfar and al. in Tunis with the lowest rate: 1 in 21,439 births [2]. This difference is explained by the socio-economic level of the country and by the quality of the surveillance of pregnancy and childbirth [16] [17] [18] but also by the high prevalence of sexually transmitted diseases as well as abortions in septic conditions, causing tubal lesions, frequently observed in Africa [19].

Reported in some publications, the incidence in the black race is up to 10 to 25 times that of the white race [10] [20] [21]. A few cases have been reported on assisted reproduction [22] [23].

Women over 30 with few deliveries are much more eligible according to the literature [24].

\subsection{Pathogenesis}

There are several classifications of abdominal pregnancies. Among these classifications, the oldest distinguishes the primitives from the secondaries [11].

The primary form is the least frequent [25]. By delay in oocyte uptake, the ovum can remain in the free peritoneum until the 6th day after ovulation and can be fertilized and nest on any structure of the cavity [26]. Confirmation of this form must meet the four conditions of Studdiford [2] [11] namely both 
tubes and ovaries must be free from any lesion; absence of utero-peritoneal fistula; the relations of the ovular sac concern exclusively the peritoneal surface; the pregnancy must be young enough.

More frequent, the secondary form can result from a ruptured tubal pregnancy or from a tubo-abdominal abortion and can be consecutive to a secondarily abdominal intrauterine pregnancy on the occasion of a ruptured hysterotomy scar, a breach of uterine perforation, or a rupture of a rudimentary horn [2].

A new classification based on gestational age or location of implantation has been proposed by certain Anglo-Saxon authors [27]. It distinguishes early abdominal pregnancy whose gestational age is less than 20 weeks with a trophoblastic implantation which takes place mainly on the uterus, the broad ligament, the parietal peritoneum and the dead end of Douglas, from pregnancy late abdominal pain after 20 weeks [11].

\subsection{Diagnostic}

We will discuss the diagnosis both clinically and paraclinically.

Clinically, the diagnosis is guided by several symptoms [28] [33]:

- digestive disorders: nausea, vomiting, constipation, subocclusion;

- abdomino-pelvic pain concomitant with fetal movements with or without metrorrhagia;

- anemia with deterioration of the general condition;

- a very superficial fetus often in an atypical, high transverse position;

- sometimes palpation of the uterus increased in size but empty corresponding to a second mass;

- on vaginal examination, the cervix is often fixed under the pubic symphysis, it is hard and long;

- it is not uncommon for a progressive complication to dominate the picture (internal or externalized hemorrhage, anemia, jaundice, oliguria, toxi-infectious syndrome).

Our patient presented many of these signs supporting the diagnosis.

Paraclinically, our diagnosis was confirmed by abdominal ultrasound. But in case of occlusive syndrome or an atypical position of the fetus, the X-ray of the abdomen without preparation is indicated. However, the key examination remains laparoscopy [29], inaccessible in all hospital structures in the country.

\subsection{Treatment}

The only therapeutic sanction used to manage an abdominal pregnancy is surgery, the operational urgency of which is theoretically qualified according to fetal viability [2].

A preventive laparotomy was performed at $34 \mathrm{WA}+2$ days in our case in order to avoid the risk of maternal-fetal mortality. Despite this, the newborn baby died a few days after prematurity and neonatal infection.

Because of the risk of cataclysmic hemorrhage, all attempts at placental extir- 
pation are strictly prohibited, especially if the placenta is inserted into a noble organ or a vessel [30]. The placenta is left in place but by cutting the cord as close as possible and by strictly monitoring the patient postoperatively in order to detect complications (fistula, peritonitis, abscess, secondary hemorrhage, occlusion). Ultrasound coupled with the dosage of placental hormones [4] makes it possible to control spontaneous placental resorption which takes place in two phases, namely very slow until the 10 th week and faster which could last up to 3 years [31].

In order to accelerate this absorption, we used an antimitotic (Methotrexate). But this attitude is still discussed in the literature not only because of its toxicity but also of its inability to avoid the complications caused [28]. In the meantime, whole blood bags were donated and drains put in place. Thromboprophylaxis under platelet control was started for 10 days as well as iron supplementation for one month. It should be noted that during the operation, antibiotic prophylaxis was also administered.

\subsection{Maternal-Fetal Prognosis}

The fetal prognosis of abdominal pregnancy is poor with mortality ranging between $75 \%$ and $95 \%$ due to poor placental vascularity, hypotrophy and fetal malformations [32].

On the other hand, the prognosis of the mother depends for its part on the delay in diagnosis and the attitude towards the placenta; maternal mortality is of the order of $0 \%$ to $18 \%$ according to Hainaut [11].

\section{Conclusion}

Rare, abdominal pregnancy is an obstetric emergency requiring special attention. For this, the pregnant woman has the obligation to benefit from a wellfollowed prenatal consultation by competent personnel capable of detecting abnormalities of the abdominal pregnancy and of prescribing an adequate treatment because certain pathologies are likely to compromise the life of the mother or of the fetus.

\section{Conflicts of Interest}

The authors declare no conflicts of interest regarding the publication of this paper.

\section{References}

[1] Partingon, C.K., Studley, J.G.N. and Menzies-Gow, N. (1986) Abdominal Pregnancy Complicated by Appendicitis. Case Report. British Journal of Obstetrics and Gynaecology, 93, 1011-1012. https://doi.org/10.1111/j.1471-0528.1986.tb08028.x

[2] Sfar, E., Kaabar, H., Marrakechi, O., et al. (1993) La grossesse abdominale, entité anatomo-clinique rare. A propos de 4 cas (1981-1990). Revue française de gynécologie et d' obstétrique, 88, 261-265.

[3] Lansac, J., Lacomte, P. and Marret, H. (2014) Gynécologie pour le praticien. 8è edi- 
tion, Elsevier Masson, Amsterdam, 167.

[4] Martin Jr., J., Sessums, J., Martin, R., Pryor, J. and Morrisson, J. (1988) Abdominal Pregnancy: Current Concepts of Management. Obstetrics \& Gynecology, 71, 549-557.

[5] Le Lorier, G., Shebat, C. and Wencel, S. (1969) La grossesse abdominale au voisinage du terme avec enfant vivant. Problèmes diagnostiques et thérapeutiques, à propos d'un cas. Bull Fed Soc. Gynecol Obstet, 21, 382-399.

[6] Loffredo, V., Tesquier, L., Paris, F.X. and Debrux, J. (1984) La grossesse extrautérine. Encyl Med Chir Gynécologie, 700, 6.

[7] Correa, P., Atayi, L., Cave, L., Lauroy, L. and Bourgoin, P. (1965) Quelques aspects particuliers de la grossesse abdominale. A propos de 18 cas relevés en milieu africain à Dakar. Bull Fed Gynecol Obstet, 17, 872-874.

[8] Correa, P., Diadhiou, F., Lauroy, J., Bah, M.D., Diab, A. and Guindo, S. (1979) Evolution exceptionnelle de la grossesse abdominale. The Journal de Gynécologie Obstétrique et Biologie de la Reproduction, 8, 235-241.

[9] Diouf, A., Diouf, F., Cisse, C.T., Diako, D., Gaye, A. and Diadhiou, F. (1996) La grossesse abdominale à terme avec enfant vivant. A propos de 2 observations. The Journal de Gynécologie Obstétrique et Biologie de la Reproduction, 25, 212-215.

[10] Duchamp de Chastaigne, M. and Mezin, R. (1994) Association grossesse abdominale-grossesse intra-utérine au troisième trimestre. A propos d'un cas et revue de la littérature. The Journal de Gynécologie Obstétrique et Biologie de la Reproduction, 23, 440-443.

[11] Hainaut, F., Mayenga, J.M. and Crimail, P.H. (1991) Grossesse abdominale tardive. A propos d'un cas. Revue française de gynécologie et d’ obstétrique, 86, 522-528.

[12] Picaud, A., Ella-Ekogha, R., Ozouaki, F., Nlome-Nze, A.R., et al. (1990) Grossesse abdominale. A propos de 11 cas. Médecine d' Afrique noire, 37, 483-487.

[13] Renaud, R., Voury-Heyler, C., Leissner, P., Chesnet, Y., et al. (1969) Bondurand. Les grossesses abdominales après le 6è mois. Revue de la littérature. A propos de 8 cas. Gynecology and Obstetrics, 68, 297-318.

[14] Setouani, A., Snaibi, A. and Boutaleb, Y. (1989) La grossesse abdominale. The Journal de Gynécologie Obstétrique et Biologie de la Reproduction (Paris), 18, 177-180.

[15] Tanoh, L., Ba, L., Djanhan, Y., Ayadho, Y., et al. (1988) A propos de 11 cas de grossesse abdominale colligés en 4 ans. Compte rendu de la Société de GynécologieObstétrique de Cote d'Ivoire. The Journal de Gynécologie Obstétrique et Biologie de la Reproduction, 17, 934.

[16] Alto, W.A. (1990) Abdominal Pregnancy. American Family Physician, 41, 209-214.

[17] Christalli, B., Guichaoua, Heid, M., Izard, V. and Levardon, M. (1992) Grossesse ectopique abdominale. Limites du traitement cœlioscopique. The Journal de Gynécologie Obstétrique et Biologie de la Reproduction, 21, 751-753.

[18] Guermazi, S. (1985) A propos de 2 cas de grossesse abdominale observés à l'hôpital Charles Nicolle de Tunis. Thèse méd, Sfax.

[19] Iloki, L.H., Koubaka, R., Nkikouabonga-Guinot, G., Ibara, J.R., Ekoundzola, J.R. and Itoua-Ngaporo, A. (1999) Grossesse Abdominale. Neuf cas colligés en 4 ans (1991/ 1995) au CHU de Brazzaville (Congo). Revue française de gynécologie et dobstétrique, 94, 40-43.

[20] Ham Dan, M., Rousseau, G. and Wagner, J. (1991) Grossesse abdominale. Un cas d'autochtone avec enfant à terme, vivant et normal. Journal de Chirurgie, 128, 544-547.

[21] Benvold, E. and Raab, N. (1983) Abdominal Pregnancy: A Case Report and a Brief 
Review of the Littérature. Acta Obstetricia et Gynecologica Scandinavica, 62, 377-379. https://doi.org/10.3109/00016348309156244

[22] Vignali, M., Busacca, M., Brignate, C., Doldi, N., Spagnolo, D. and Belloni, C. (1990) Abdominal Pregnancy as a Result of Gamete Intrafallopian Transfer and a Subsequent Treatment with Methotrexate: A Case Report. International Journal of Fertility, 35, 280-283.

[23] Ferland, R.J., Chadwick, D.A., O’Brien, J.A. and Granal, C.O. (1991) An Ectopic Pregnancy in the Upper Retroperitoneum Following in Vitro Fertilization and Embryotransfer. Obstetrics \& Gynecology, 78, 544-546.

[24] Leikin, E. and Randall, H.W. (1987) Hydrocephalic Fœtus in an Abdominal Pregnancy. Obstetrics \& Gynecology, 69, 498-500.

[25] Cetin, M.T., Aridogan, N. and Coskun, A. (1992) La grossesse abdominale. A propos de six cas personnels. Revue française de gynécologie et d̊ obstétrique, 87, 76-78.

[26] Bouaziz, N., Zhioua, F., Chaker, A., Mouelhi, C., Ferchiou, M. and Meriah, S. (1997) Un nouveau cas de grossesse abdominale avec enfant vivant et non malformé. Tunisie Médicale, 75, 143-145.

[27] Martin, J.N. and McCaul, J.F. (1990) Emergent Management of Abdominal Pregnancy. Clinical Obstetrics and Gynecology, 33, 438-447. https://doi.org/10.1097/00003081-199009000-00008

[28] Bouzid, F., Cellami, D., Baati, S., Chaabouni, M., Triki, J., Lamine, L. and Rekiki, S. (1996) La grossesse abdominale. Rev. Fr. Gynécol. Obstétr., 91, 616-618.

[29] Rajaonarison, T.J. (2004) Grossesse abdominale sur rupture progressive d'un utérus cicatriciel: À propos d'un cas. Thèse de doctorat en Médecine, 25.

[30] Akpadza, K., Baeta, S., Oureya, H., Wozufia, F. and Hodonou, A. (1996) Grossesse abdominale et grossesse intrautérine simultanée à terme avec enfants vivants: Un cas. Rév. Fr. Gynécol. Obstétr., 91, 322-324.

[31] Belfar, H. (1986) Long Term Fellow-Up after Removal of Abdominal Pregnancy. Journal of Ultrasound in Medicine, 5, 521-523. https://doi.org/10.7863/jum.1986.5.9.521

[32] Poizat, R. and Lewin, F. (1982) Grossesse extra-utérine après le 5è mois. Encyl Méd Chir Obstétrique, 5069, 5.

[33] Sepou, A., Yanza, M.C. and Nguembi, E. (2003) Aspects épidémiologiques et cliniques de 116 cas de GEU. Médecine d'Afrique noire, 50. 